\title{
PENGARUH KEPEMIMPINAN, MOTIVASIDAN BUDAYA ORGANISASI TERHADAP KINERJA KARYAWAN PT BENTARA SINERGIES MULTIFINANCE (BESS FINANCE) (STUDI KASUS DI CABANG TANGERANG)
}

\author{
M. Anton Nurhidayat \\ Universitas Pamulang \\ Email: antonasgar91@yahoo.com
}

\begin{abstract}
ABSTRAK.
Tujuan dari penelitian ini adalah untuk mengetahui Pengaruh Kepemimpinan, Motivasi dan Budaya Organisasi terhadap Kinerja Karyawan PT Bentara sinergies Multifinance (BESS Finance) study kasus di cabang Tangerang Devisi Mobil, baik parsial maupun simultan.

Penelitian ini menggunakan data kuantitatif dengan metode study kasus dan pengujian hipotesis. Populasi adalah karyawan yang bekerja di PT Bentara sinergies Multifinance (BESS Finance) di cabang Tangerang Devisi Mobil sebanyak 52 karyawan.Teknik sampling yang digunakan adalah teknik sampling jenuh, sehingga diperoleh sebanyak 52 karyawan. Teknik analisis data digunakan dengan: 1. Test Validitas dan Realibilitas, 2. Test Asumsi Klasik, 3. Regresi Linear Berganda, 4. Koefisien Determinasi dan 5. Pengujian Hipotesis.Berdasarakan hasil analisis yang dilaksanakan sehingga didapathasilsebagai berikut:

1. Terdapatpengaruh yang positif dan signifikan antarakepemimpinan terhadap kinerja dengan nilai $t$ hitung $>\mathrm{t}$ tabel $(5,067>1,677)$ dan signifikansi $(0,000>0,005)$. Dengan demikian menolak $\mathrm{H}_{\mathrm{o}}$ dan menerima $\mathrm{H}_{1}$, yang berarti kepemimpinan berpengaruh terhadap kinerja karyawan.

2. Terdapat nilai $t_{\text {hitung }}>t_{\text {tabel }}(6,693>1,677)$ dan signifikansi $(0,000>0,005)$. Maka menolak $\mathrm{H}_{0}$ dan menerima $\mathrm{H}_{2}$, yang berarti ada pengaruh Motivasi terhadap Kinerja.

3. Terdapat hasil $\mathrm{t}_{\text {hitung }}>\mathrm{t}_{\text {tabel }}(6,854>1,677)$ dan signifikansi $(0,000>0,005)$. Maka menolak $\mathrm{H}_{0}$ dan menerima $\mathrm{H}_{3}$, yang berarti budaya organisasiberpengaruh positif dan signifikan terhadap kinerja karyawan.

4. Terdapat pengaruh yang positif dan signifikan antara kepemimpinan, motivasi dan budaya organisasi secara simultan terhadap kinerja karyawan, dengan nilai $f_{\text {hitung }}>f_{\text {tabel }}(18,103>2,79)$ dan signifikansi $(0,000>0,005)$. Maka menolak $\mathrm{H}_{0}$ dan menerima $\mathrm{H}_{4}$, yang berarti kepemimpinan, motivasi dan budaya organisasiberpengaruh terhadap kinerja karyawan.
\end{abstract}

Kata Kunci: Kepemimpinan, Motivasi, Budaya Organisasi dan Kinerja Karyawan.

\section{ABSTRACK}

The purpose of this study is to find the influence of leadership, motivation and culture organization of the performance of an employee of PTBentaraSinergies Multifinance (bess finance) study cases in the branch tangerang devisi car, good partial and simultaneous.

This research using quantitative data with the methods study cases and the testing of hypotheses.The population is employees who worked in PT BentaraSinergies Multifinance (bess finance) in tangerang devisi the branch of the car as much as 52 employees .Sampling technique used is saturated techniques of sampling, so obtained a total of 52 employees.Data analysis techniques used by: 1. Test validity and reliability, 2.Classic test assumptions , 3 .Regression worship of idols , 4.The coefficients determined and 5 .The testing of hypotheses.

They would the results of the analysis done so obtained as follows: 

employees, with an $t$ count $>t$ table $(5,067>1,677)$ and significance of $(0,000<0,005)$. But refuse $h 0$ and receive $h 1$, which means leadership influential positive and significantly to employee performance.

Is the positive and welfare between motivation for employee performance, with an t count $>$ t table $(6,693>1,677)$ and significance of $(0,000<0,005)$. But refuse $h 0$ and receive $h 2$, which means motivation influential positive and significantly to employee performance.

Is the positive and welfare between cultures organization on performance employees, with an t count > t table (6,854>1,677) and significance of ( 0,000 < 0,005 ).But refuse $h 0$ and receive $h 3$, which means culture organization influential positive and significantly to employee performance.

Is the positive and welfare between leadership, motivation and culture organization simultaneously on performance employees, with an $f$ count $>f$ table ( $18,103>; 2,79$ ) and significance of ( 0,000 <,005). But refuse h0 and receive $h 4$, which means leadership, motivation and cultural influential organization positive and significantly to employee performan

Keyword: leadership , motivation, cultural organization, employee performanc 


\section{PENDAHULUAN}

Dengan tingkat persaingan bisnis saat ini mengakibatkanperusahaan dihadapkan pada suatu tantangan untuk selalu meningkatkan kinerja karyawannyaguna mempertahankan keberlangsungan roda perusahaan.Salah satunya adalah PT Bentara Synergies Multifinance (Bessfinance) cabang Tangerang.PT Bentara Synergies Multifinance (Bessfinance) saat ini yang berada di Serpong ini merupakan lembaga non pemerintah yang berorientasi bisnis pada pembiayaan kredit (finance) yang bergerak dalam usaha pembiayaan kredit khususnya kredit otomotif (kendaraan).Dengan peningkatan kinerja para karyawan dan kesejahteraan para karyawan menjadi focus utamadari manajemen PT Bentara Synergies Multifinance (BESS Finance).Program-program yang diberikan oleh PT Bentara synergies Multifinance (BESS Finance) di cabang Tangerangguna meningkatkan kualitas karyawannya salah satunya dengan memberikan motivasi kerja dalam bentuk insentif untuk karyawan yang dinilai mempunyai kinerja baik. Dengan adanya pemberian motivasi melalui insentif, perusahaan berharap semua karyawannyaakanselalu berlombalomba untuk meraih kinerja terbaiknya. Solusi yang direncanakan oleh perusahaan diharapkanberjalan dengan baik guna memicu peningkatan kompetensi semua karyawannya dalam pembentukan kinerja yang baik.

Berdasarkan uraian diatas, peneliti bersama dengan manajemen PT Bentara Synergies Multifinance (Bessfiance) di Serpong saat ini dapat mengurai permasalahan Sumber Daya Manusia (karyawan) yang cukup serius dimana terdapat permasalahan pada kepemimpinan perusahaan, motivasi kerja karyawanserta budaya organisasi perusahaan yang redah. Hal ini masih dapat dijumpai adanya karyawan yang sering terlambat hadirdengan berbagai macam alasan diantaranya jarak rumah menuju kantor yang jauh dan kurangnya ketegasan seorang pemimpin dalam memberikan sanksi kepada karyawan yang terlambat namun hal itu dikarenakan seorang pemimpinnyapun selalu datang terlambat dari jam kerja yang ditentukan perusahaan sehingga menjadi faktor utamamenurunnyasemangat bekerja bagi sebagian para karyawannya. Jika permasalahan ini terus berlangsung, maka alasan faktor jarak rumah ke kantormenjadi senjata bagi sebagian karyawan menjadi kurang disiplin. Faktor selanjutnya yang mengakibatkan karyawan menjadi malas kerja adalah rutinitas kerja yang monoton atau itu itu saja, sehingga dapat menimbulkan kejenuhan kerja karyawan. Hampir setiap hari karyawan dituntut mengerjakan pekerjaan yang sama dan berulang-ulang. Permasalahan ini juga dapat menurunkan semangat dan konsentrasi bekerja karyawannya sehingga diperlukan pembaharuan motivasi dengan membuat suasana kerja yang variatif.

Dengan memaparkan permasalahan-permasalahan diatas, penulis sangat tertarik guna melakukan penelitian secara lebih mendalam pada PT Bentara Synergies Multifinance (Bessfinance) yangberjudul, "Pengaruh Kepemimpinan, MotivasiKerja sertaBudaya Organisasi terhadap Kinerja Karyawan pada PT Bentara Synergies Multifinance (Bessfinance)" study kasus di cabang Tangerang Devisi Mobil

\section{KERANGKA PEMIKIRAN}

Dalam bukunya Manulang (Atik \& Ratminto, hal. 2012: 1) menjabarkan manajemen sebagai "seni dan ilmu perencanaan (planning),pengorganisasian (organization), pengarahan (actuating), dan pengawasan (controlling)pada sumber dayamanusia guna mencapai 
tujuan yang telah ditetapkan terlebih dahulu".

$\begin{array}{cr}\text { Malayu S.P } & \begin{array}{r}\text { Hasibuan } \\ \text { bahwa }\end{array}\end{array}$

Manajemen Sumber Daya Manusia adalah "ilmu dan seni mengatur hubungan dan peranan tenaga kerja agar efektif dan efisien membantu terwujudnya tujuan perusahaan, karyawan dan masyarakat". Anoraga

Kepemimpinan diartikan sebagai "kemampuan seseorang untuk dapat mempengaruhi orang lain, melalui komunikasi baik secara langsung maupun tidak langsung dengan maksud untuk menggerakkan orang-orang tersebut agar dengan penuh pengertian, kesadaran dan senang hati bersedia mengikuti kehendak-kehendak pemimpin itu".

Sudarwan Danim (2001:25) Mengemukakan bahwa "motivasi ialah kondisi psikologis dari hasil interaksi kebutuhan karyawan dan faktor luar yang mempengaruhi perilaku seorang karyawan". Selanjutnya motivasi menurut Berelson dan Stainer (2002 :67) diartikan sebagai“"keadaan kejiwaan dan sikap mental manusia yang memberikan energi, mendorong kegiatan dan mengarahkan perilaku kearah mencapai kebutuhan yang memberi kepuasan".

Robbins \& Coulter (2010: 63) mengemukakan bahwa "Budaya organisasi atau organizational culture adalah sehimpunan nilai, prinsip, tradisi dan cara bekerja yang dianut bersama oleh dan mempengaruhi perilaku serta tindakan para anggota organisasi”. Dalam kebanyakan organisasi, nilainilai dan praktik- praktik yang dianut bersama (shared) ini telah berkembang pesat seiring dengan perkembangan zaman dan benar- benar sangat mempengaruhi bagaimana sebuah organisasi dijalankan.

Menurut Mangkunegara, (2009:18) Kinerja karyawan (prestasi kerja) adalah hasil kerja secara kualitas dan kuantitas yang dicapai oleh seorang pegawai dalam melaksanakan tugasnya sesuai dengan tanggung jawab yang diberikan kepadanya.

Tingkat keberhasilan suatu kinerja meliputi aspek kuantitatif dan kualitatif.Sedangkan, dalam bukunya Muhammad Sandy (Siswanto, 2015:11) mengungkapkan bahwa kinerja ialah prestasi yang dicapai oleh seseorang dalam melaksanakan tugas dan pekerjaan yang diberikan kepadanya. Menurut Henry Simamora (2005:327), kinerjadiartikan sebagai pencapaian persyaratan pekerjaan tertentu yang akhirnya secara langsung dapat tercermin dari outputyang dihasilkan.

\section{Hipotesis}

Menurut Suharsimi Arikunto (2006:71) hipotesis merupakan "suatu jawaban yang bersifat sementara terhadap permasalahan penelitian, sampai terbukti melalui data yang terkumpul". Oleh karena itu, hipotesis juga dapat disajikan sebagai jawaban teoritis untuk desain masalah penelitian dan tidak ada jawaban empiris.

\section{Berdasarkan kerangka} pemikiran yang sudah dikemukan diatas, maka diajukan rumus hipotesis sebagai jawaban sementara yang akan diuji dan dibuktikan kebenarannya. Rumusan hipotesisnya sebagai berikut:

1. $\mathrm{H}_{0}$ : Tidak terdapat pengaruh positif dan signifikanantara kepemimpinanterhadapkinerja karyawan PT Bentara Sinergies Multifinance (bessfinance).

$\mathrm{H}_{\mathrm{a}}$ : Terdapat pengaruh positif dan signifikan antara kepemimpinanterhadapkinerja karyawan PT Bentara Sinergies Multifinance (bessfinance).

2. $\mathrm{H}_{0}$ : Tidak terdapat pengaruh positif positif dan signifikan antara motivasiterhadapkinerja karyawan 
PT Bentara Sinergies Multifinance (bessfinance).

$\mathrm{H}_{\mathrm{a}}$ : Terdapat pengaruh positif dan signifikan antara motivasiterhadapkinerja karyawan PT Bentara Sinergies Multifinance (bessfinance).

3. $\mathrm{H}_{0}$ : Tidak terdapat pengaruh positifdan signifikanantara budaya organisasiterhadapkinerja

karyawan PT Bentara Sinergies Multifinance (bessfinance).

$\mathrm{H}_{\mathrm{a}}$ : Terdapat pengaruh positif dan signifikan antara budaya organisasiterhadapkinerja

karyawan PT Bentara Sinergies Multifinance (bessfinance).

4. $\mathrm{H}_{0}: \rho_{1,2}=0$, artinya tidak terdapat pengaruh yang positif dan signifikan antara kepemimpinan, motivasi dan budaya organisasi (X1, X2 dan X3) secara simultan terhadap kinerja karyawan (Y).

$H_{a}: \rho_{1,2} \neq 0$, yang berarti ada pengaruh yang positif dan signifikan antara kepemimpinan, motivasi dan budaya organisasi (X1, X2 dan X3) secara simultan terhadap kinerja karyawan (Y).

\section{METODE PENELITIAN}

Menurut sugiyono dalam bukunya Metodologi Penelitian dan Administrasi dinyatakan: Penelitian menurut tingkat eksplanasinya adalah "penelitian yang bermaksud menerangkan kedudukan variabelvariabel yang diteliti serta hubungan antara satu variabel dengan variabel yang lain". Dalam hal ini peneliti menggunakan penelitian asosiatif. Menurut Sugiyono (2012:11) penelitian asosiatif merupakan penelitian yang bertujuan untuk mengetahui pengaruh atau hubungan antara dua variabel atau lebih.

Penulis dalam penelitian ini menggunakan data kuantitatif yaitu data yang berbentuk angka (skoring) atau data kualitatif yang diangkakan. Setelah menguji normalitas dilakukan uji korelasi untuk mengetahui ada tidak nya hubungan antar variabel bebas $(\mathrm{X} 1=$ kepemimpinan, $\mathrm{X} 2=$ motivasi, $\mathrm{X} 3=$ budaya organisasi) terhadap variabel terikat (Y Kinerja) seperti model dibawah ini :

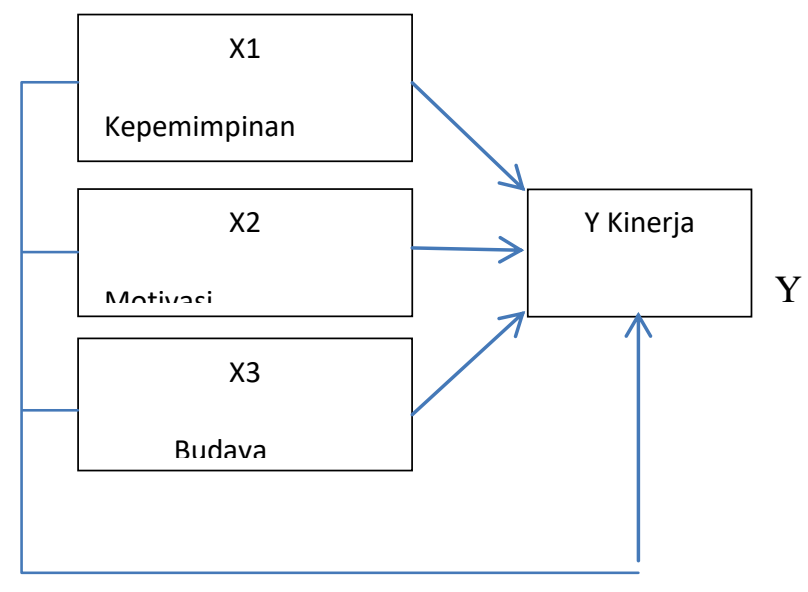

$\mathrm{X} 1, \mathrm{X} 2, \mathrm{X} 3$

HASIL

Uji validitas dalam penelitian ini mendapatkan hasil pada masing-masing indikator dari variabel memiliki nilai korelasi > 0,281, ini dapat diartikan bahwa kuisioner yang digunakan layak untuk mengumpulkan data sebab pertanyaan yang dipakai dalam kuesioner dalam mengukur variabel yang diteliti memiliki ketepatan yang valid.

Uji Reliabilitas digunakan untuk mengukur seberapa andal suatu instrument digunakan dalam penelitian. Penelitian ini menggunakan koefisien cronbach's alpha. Instrument dinyatakan reliabel (layak) apabila memiliki nilai cronbach's alpha lebih 
besar dari 0,6 dan dikatakan tidak reliable jika cronbach's alpha<0,06 (Ghazali ,2005). Hasil uji reliabilitas mendapatkan hasil bahwa nilai Cronbach's Alpha untuk setiap variabel $>0,6$ yang berarti pengukuran tersebut dapat memberikan hasil yang konsisten jika kembali digunakan untuk mengukur subyek yang sama.

Uji normalitas dilakukan dengan dengan "Normal P-P Plot".Pada Normal P-P Plot prinsipnya dapat dideteksi dengan melihat penyebaran data (titik) pada sumbu diagonal grafik atau dengan melihat histogram dari residualnya. Dasar pengambilan keputusan:

1) Jika kurva garis diagonal atau histogram menyebar melintasi garis diagonal makadengan demikianbentukregresi memenuhi asumsi normalitas.

2) Jika data didistribusikan menjauhidan / atau tidak mengikuti secara diagonal atau jika grafik distribusi normal tidak ditemukan dalam histogram, model regresi tidak memenuhi asumsi normal.

Menurut Ghozali (2007:134)Uji Multikolinearitas"bertujuan untuk menguji apakah model regresi ditemukan adanya korelasi antar variabel bebas (independen). Model regresi yang baik seharusnya tidak terjadi korelasi di antara variabel independen. Jika variabel independen saling berkolerasi, maka variabelvariabel ini tidak orthogonal". Metode yang dipakai untuk menguji keberadaan multikolinieritas pada penelitian ini dengan menggunakan toleransi dan varians inflasi faktor (VIF). Jika angka VIF (variance inflation factor) $>10$ dan nilai toleransi $<0,10$, sehinggadinyatakan

adaMultikolinearitas.

PengujianHeteroskedastisitas ini digunakan untuk melihat apakah variabel pengganggu mempunyai varian yang sama atau tidak. Bukti ada atau tidak adanya heteroskedastisitas menunjukkan ada atau tidaknya pola tertentu dalam grafik antara SRESID dan ZPRED, di mana sumbu $Y$ diprediksi untuk $\mathrm{Y}$ dan sumbu $\mathrm{X}$ adalah residu yang dipelajari ( $\mathrm{Y}$ diprediksi - Yasli) . Analisis dasarnya adalah:

1) Jika model yang diberikan ada, karena titik yang ada membentuk model spesifik yang normal (bergelombang, meluas, dan mengecil), ini menunjukkan bahwa telah terjadi heterodisplisitas.

2) Jika modelnya jelas dan angka-angka meluas di atas dan di bawah angka 0 pada sumbu Y, tidak ada heteroskedastisitas terjadi.

\section{PEMBAHASAN}

Agar memudahkan
dalampengkajiandarianalisis yang dilaksakan, akan diterangkan pengaruh dari masing-masing variabel bebas yang melipti kepemimpinan, motivasi dan budaya organisasi terhadap kinerja karyawan.

\section{Pengaruh Kepemimpinan terhadap Kinerja karyawan}

Dari hasil uji regresi secara parsial, pengaruh kepemimpinan (X1) terhadap kinerja karyawan (Y) menghasilkan nilai $t_{\text {hitung }}$ sebesar 5,067 maka nilai tersebut lebih besar dari nilai $\mathrm{t}_{\text {tabel }} 1,677\left(\mathrm{t}_{\text {hitung }} 5,067>\right.$ $t_{\text {tabel }} 1,677$ ) dan nilai sig. hitung 0,000 $<0,05$. Dengan demikian bahwa kepemimpinan berpengaruh positif dan signifikan terhadap kinerja karyawan terbukti.

\section{Pengaruh motivasi terhadap} kinerja karyawan

Dari hasil uji regresi secara parsial, pengaruh motivasi (X2) terhadap kinerja karyawan (Y)diperoleh nilai t hitung 6,693dengan demikian lebih besar dari nilai $t_{\text {tabel }} 1,677$. Besarnya nilai $t_{\text {hitung }}>t_{\text {tabel }}$ mengindikasikan 
bahwa pengaruhnya signifikan dan nilai sig. hitung $0,000<0,05$.

3. Pengaruh budaya organisasi terhadap kinerja karyawan

Dari hasil uji regresi, pengaruh budaya organisasi (X3) terhadap kinerja karyawan (Y)diperoleh nilai $\mathrm{t}_{\text {hitung }} 6,854$ maka nilai tersebut lebih besar dari nilai $t_{\text {tabel }} 1,677$. Besarnya nilai $t_{\text {hitung }}>t_{\text {tabel }}$ mengindikasikan bahwa pengaruhnya signifikan dan nilai sig. hitung $0,000<0,05$.

\section{Pengaruh kepemimpinan, motivasi} dan budaya organisasi terhadap kinerja karyawan.

Dari hasil olah data diatas akan menjelaskan pengaruh Kepemimpinan (X1) Motivasi (X2) dan Budaya organisasi (X3) terhadap KInerja karyawan (Y) secara simultan (bersama-sama) menghasilkan nilai $\mathrm{F}$ hitung sebesar 18,103 sedangkan Ftabel 2,79. maka data tersebut dapat dikatakan terjadi pengaruh positif secara simultan ( $\mathrm{F}_{\text {hitung }} 18,103>\mathrm{F}_{\text {tabel }} 2,79$ ). Apabila dihitung dari nilai signifikasi menghasilkan nilai sig. $0,000<$ 0,05 maka hasil yang di dapat berpengaruh secara signifikan.Dengan demikian hipotesis yang menyatakan bahwa kepemimpinan, motivasi dan budaya organisasi berpengaruh positif dan signifikan terhadap kinerja karyawan terbukti.

\section{KESIMPULAN}

Dari hasil pengujian dan analisa pada bab terdahulu dapat diambil kesimpulan sebagai berikut:

1. Pengaruh Kepemimpinan terhadap Kinerja karyawan

1. Dari hasil uji regresi secara parsial, pengaruh kepemimpinan (X1) terhadap kinerja karyawan (Y) menghasilkan nilai $\mathrm{t}_{\text {hitung }}$ sebesar 5,067 maka nilai tersebut lebih besar darinilai $\mathrm{t}_{\text {tabel }} 1,677$ ( $\mathrm{t}_{\text {hitung }}$ $\left.5,067>t_{\text {tabel }} 1,677\right)$ dan nilai sig. hitung $0,000<$ 0,05 . Dengan demikian hipotesis yang menyatakan bahwa kepemimpinan berpengaruh positif dan signifikan terhadap kinerja karyawan terbukti. Besarnya pengaruh sebesar $33,9 \%$ sisanya $66,1 \%$ dipengaruhi faktor lain.

2. Pengaruh motivasi terhadap kinerja karyawan.

Dari hasil uji regresi secara parsial, pengaruh motivasi (X2) terhadap kinerja karyawan (Y) menghasilkan nilai $\mathrm{t}$ hitung sebesar 6,693 maka nilai tersebut lebih besar dari nilai $\mathrm{t}_{\text {tabel }} 1,677$. Besarnya nilai $\quad t_{\text {hitung }}>\quad t_{\text {tabel }}$ mengindikasikan bahwa pengaruhnya signifikan dan nilai sig. hitung $0,000<$ 0,05 . Dengan demikian hipotesis yang menyatakan bahwa motivasi berpengaruh positif dan signifikan terhadap kinerja karyawan terbukti. Besarnya pengaruh sebesar $47,3 \%$ sisanya $52,7 \%$ diepengaruhi faktor lain. Pengaruh budaya organisasi terhadap kinerja karyawan

3. Dari hasil uji regresi secara parsial, pengaruh budaya organisasi (X2)terhadap kinerja karyawan (Y)menghasilkan nilai $t_{\text {hitung }}$ sebesar 6,854nilai tersebut lebih besar dari nilai $t_{\text {tabel }} 1,677$. Besarnya nilai $t_{\text {hitung }}>t_{\text {tabel }}$ mengindikasikan bahwa 
pengaruhnya signifikan dan nilai sig. hitung 0,000 $<0,05$. Dengan demikian hipotesis yang menyatakan bahwa budaya organisasi berpengaruh positif dan signifikan terhadap kinerja karyawan terbukti. Besarnya pengaruh sebesar $48,4 \%$ dan sisanya $51,6 \%$ diepengaruhi faktor lain.

4. Hasil olah data diatas akan menjelaskan pengaruh

Kepemimpinan Motivasi (X2) dan Budaya organisasi (X3) terhadap Kinerja karyawan (Y) secara simultan (bersamasama) menghasilkan nilai $\mathrm{F}$ hitung sebesar 18,103 sedangkan Ftabel 2,79. maka data tersebut dapat dikatakan terjadi pengaruh positif secara simultan ( $\mathrm{F}_{\text {hitung }} 18,103>\mathrm{F}_{\text {tabel }} 2,79$ ). Apabila dihitung dari nilai signifikasi menghasilkan nilai sig. $0,000<0,05$ maka hasil yang di dapat berpengaruh secara signifikan. Dengan demikian hipotesis yang menyatakan bahwa kepemimpinan, motivasi dan budaya organisasi berpengaruh positif dan signifikan terhadap kinerja karyawan terbukti. Besarnya pengaruh sebesar $50,2 \%$ dan sisanya 49,8 dipengarihi faktor lain.

\section{DAFTAR PUSTAKA}

Abdullah,ma'ruf. 2014. Manajemen dan evaluasi kinerja karyawam, jakarta, aswaja pressindo.

Ambar Teguh Sulistiyani dan Rosidah. 2003. Manajemen Sumber Daya

\author{
Manusia,Graha \\ Ilmu:Yogyakarta.
}

Amstrong, Michael. 2003, Strategic HumanResource Management.

Terjemahan

Atit Cahayani. Jakarta:

PT.Bhuana Ilmu Populer

Andreas, Lako. 2004. Kepemimpinan dan Kinerja Organisasi Isu Teori dan Solusi, Yogyakarta, Amara

Books

Anoraga, Pandji.2003. Psikologi Kepemimpinan. Jakarta: Rineka Cipta Agoes, Cenik. Ardana. 2009. Etika Bisnis dan Profesi. Salemba Empat: Jakarta

Arep, Ishak dan Hendri, Tanjung. 2003. Manajemen Sumber Daya Manusia. Jakarta: Universitas Trisakti.

Arikunto, Suharsimi. 2006. Prosedur Penelitian Suatu Pendekatan Praktek. Jakarta: Rineka Cipta.

Assauri, Sofjan. 2004. Manajemen Pemasaran. Jakarta: Rajawali Press.

Brahmasari, Ida Ayu dan Suprayetno,Agus.2008.

"Pengaruh Motivasi Kerja, Kepemimpinan dan Budaya Organisasi Terhadap Kepuasan Kerja Karyawan serta Dampaknya pada Kinerja Perusahaan (Studi Kasus pada PT. Pei Hai International Wiratama Indonesia). Dalam Jurnal Manajemen dan Kewirausahaan, Universitas 17 Agustus Surabaya, Vol.10, No.2,September 2008:124135. 
Berelson dan G,A,Steiner.2002.Human Behavior : an Inventory of Scientific Findings.New York: Harcourt, Brace \& World, Inc.

Bohlander, George., and Snell, Scott. 2010. Principles of Human Resource. Management, 15th ed. Mason, OH: South Western-Cengage Learning

Danim, Sudarwan. 2001. Motivasi Kepemimpinan dan Efektivitas Kelompok. Jakarta:PT Rineka Cipta Utama.

Deal, T. E., \& Kennedy, A. A. 1992. Corporate culture: The rites and rituals ofcorporate life. Massachusetts: AddisonWesley.

Desianty, Sovyia.2005. "Pengaruh Gaya Kepemimpinan Terhadap Komitmen Organisasi Pada PT.Pos Indonesia (Persero) Semarang". Jurnal Studi Manajemen dan Organisasi, $\mathrm{Vol}$ 2,No 1, Januari,2005.

Dessler, Gary.2005. "Human Resource Management".Pearson Prentice Hall.

Dubrin Andrew J.2005. Leadership (Terjemahan). Edisi Kedua. Jakarta: Prenada Media.

Dzulkifli, Muhammad. 2011. "Pengaruh Gaya Kepemimpinan, Motivasi, Disiplin Kerja, Kompetensi dan Budaya Organisasi terhadap Kinerja Pegawai Direktorat Budidaya dan Pascapanen Florikultutra Pasar Minggu Jakarta Selatan", Skripsi Mahasiswa Universitas Negeri Syarif Hidayatullah.

Edwin B. Flippo, Terjemahan Moh. Masud, Manajemen Personalia,
1998, Edisi 6, Jilid 1, Penerbit Erlangga.

Ghozali, Imam. 2011. "Aplikasi Analisis Multivriate dengan Program SPSS".Semarang: Badan Penerbit Universitas Dipenogoro.

Gibson JL, Ivancevich JM, Donnely Jr. JH, 2003. Organizations. 8th ed., Boston, Massachusetts, Irwin, Inc.

Gomes, Cardoso, Faustino, 2006. Manajemen Sumber Daya Manusia, Andi, Jakarta.

Hadi, Sutrisno, 2003. Bimbingan Menulis Skripsi Thesis Jilid II, Penerbit Fakultas Ekonomi UGM., Yogyakarta

Handoko, Hani. 2009. Manajemen Personalia dan Sumber Daya Manusia.Yogyakarta: BPFE UGM.

Handoko, T. Hani, 2008. Manajemen Personalia Sumber Daya Manusia, Edisi Kedua,Yogyakarta, Penerbit : BPFE.

.2000, Manajemen, Cetakan Duapuluh,Yogyakarta : Penerbit BPEE.

Hasan, Iqbal. 2006. Analisis Data Penelitian dengan Statistik.Jakarta:Bumi Aksara

Hasibuan,S.P Malayu. 2008. Manajemen Dasar, Pengertian dan Masalah. Jakarta:Bumi Aksara.

$$
\text { 2007, Manajemen }
$$
Sumber Daya Manusia, Jakarta, Bumi Aksara. 
\begin{tabular}{lr}
.2006. & Manajemen \\
sumber & Daya \\
Manusia,BumiAksara:Jakarta. & \\
\hline 2003. Organisasi dan
\end{tabular} Motivasi, Dasar Peningkatan Produktivitas. Jakarta Bumi Aksara.

2001.

Manajemen Sumber Daya Manusia Edisi Revisi. Jakarta: Bumi Aksara.

Herman Sofyandi, 2009, Manajemen Sumber Daya

Manusia.terjemahan.

Jakarta,PT. Prenhallindo.

Ilyas.Y, 2001. Kinerja Teori Penilaian \& Penelitian. Pusat Kajian Ekonomi Kesehatan FKM UI,Depok.

Istijanto. 2008. Riset Sumber Daya Manusia. Edisi ketiga. Jakarta : PT. GramediaPustaka.

Kartiningsih. 2007. Analisis Pengaruh Budaya Organisasi dan Keterlibatan Kerja terhadap Komitmen Organisasi dalam Meningkatkan Kinerja Karyawan. (Studi Pada PT. Bank Tabungan Negara (Persero) Cabang Semarang). Tesis,Undip Semarang.

Kottler, J.P., \& Heskett. J.L. 1992. Corporate culture and performance. New York: The Free Press.

Kreitner, Robert and Angelo Kinicki, 2001. Organizational Behavior. Fifth Edition. Irwin McGrawHill.

Mangkunegara, Anwar Prabu. 2002.Manajemen Sumber Daya
Manusia.Perusahaan. Bandung: PT. Remaja Rosdakarya.

Mangkunegara, Anwar Prabu. 2009. Manajemen Sumber Daya Manusia. Bandung: PT. Remaja Rosdakarya.

Mangkunegara, Anwar Prabu, 2000, Manajemen Sumber Daya Manusia Perusahaan, Cetakan Ke-2, PT. Remaja Rosda Karya, Bandung.

Mathis Robert L. dan Jackson John H. 2006, Human Resource Management, alih bahasa. Salemba Empat. Jakarta.

Moeheriono. 2012. "Pengukuran Kinerja Berbasis Kompetensi". Jakarta: Raja Grafindo Persada.

Nickels William G., McHugh James M., McHugh Susan M. 1997. Understanding Business. 4th Edition. USA: McGraw Hill Comp. Inc.

Nugroho, Eko. 2004. Sistem Informasi Manajemen. ANDI.

Panggabean, Mutiara S, 2002. Manajemen Sumber Daya Manusia. Jakarta : Ghalia Indonesia.

Pasolong, Harbani. 2007. Teori Administrasi Publik. ALFABETA.

Prasetyo, Lis. " Pengaruh Gaya Kepemimpinan Terhadap Kinerja",Jurnal NeoBisnis,Vol2,No.2, Desember 2008.

Priyatno, Dwi.2012. "balajar praktis analisis parametik dan non parametik dengan SPSS cetakan pertama", Yogyakarta : Gava Media. 
Rivai, Veithzal. 2005. Manajemen Sumber Daya Manusia untuk Perusahaan : dari Teori ke Praktik. Jakarta : PT Raja Grafindo Persada.

Robbins, Stephen P., 2003. Perilaku Keorganisasian Jilid 1 Edisi 9. Jakarta: PT Indeks kelompok Gramedia.

Robbins S P \& Coulter, M. 2007, Management, Ninth Edition. New Jersey. Prentice Hall.

Robbins, Stephen P. dan Coulter, Mary. 2010. Manajemen(edisi kesepuluh). Jakarta: Erlangga.

Robbins SP, dan Judge. 2011.Perilaku Organisasi, Salemba Empat, Jakarta.

Sandy Martha, Muhammad. 2015. "Karakteristik Pekerjaan dan Kinerja Dosen Luar Biasa UIN Sunan Gunung Djati Bandung: Komitmen Organisasi Sebagai Variabel Moderating". Tesis di Universitas Widayatama Bandung.

Septi Winarsih, Atik \& Ratminto. 2012. Manajemen Pelayanan. Yogyakarta: Pustaka Pelajar.

Siagian, Sondang P. 2003. Manajemen Sumber Daya Manusia. Jakarta : Bumi aksara.

Sigit, Soehardi. 2003. Pengantar Metodologi Penelitian Sosial Bisnis Manajemen, Cetakan Ketiga, Yogyakarta: Penerbit Bagian Penerbitan Fakultas Ekonomi Universitas Sarjanawiyata Tamansiswa.

Simamora, Hendry, 1995, Manajemen Sumber Daya Manusia,Edisi Kesatu, Cetakan Pertama.

\author{
Badan Penerbit STIE, \\ Yogyakarta.
}

Simamora, Henry. 2004. Manajemen Sumber Daya Manusia, Yogyakarta: STIE YKPN.

Slamet, Achmad. 2007. Manajemen Sumber Daya Manusia. Semarang: Unnes

Press.

Stoner, J.A.F., 1982. Management.New Jersey, Prectice-Hall Inc.

Subagyo, Pangestu. 2003. Manajemen Operasi. Yogyakarta: BPFE.

Sudarmanto. 2009. Kinerja dan Pengembangan Kompetensi SDM (Teori, Dimensi Pengukuran dan Implementasi dalam Organisasi). Yogyakarta : Pustaka Pelajar.

Sugiyono. 2012. Metodologi Penelitian Bisnis. Edisi Kedua. Bandung: Alfabeta. Sugiyono, 2004, Metode Penelitian Administrasi; Bandung: CV. Alfabeta.

Sulistyani, Ambar T. dan Rosidah. 2003. Manajemen Sumber daya Manusia. Yogyakarta : Graha Ilmu.

Terry, G.R., 1978. Principle of Manajemen, $\quad 7$ th Ed.,Homewood Illinois:Richard D.Irwin Inc.

Tika, MP.2006. Budaya Organisasi dan Peningkatan Kinerja Perusahaan. Jakarta : Bumi Aksara.

Umar, Husein, 2008. Riset Sumber daya Manusia, PT. Gramedia Pustaka Utama, Jakarta.

Wahjosumidjo. 1991. Kepemimpinan yang Efektif. Yogyakarta: Balai Pustaka 
